\title{
Dictyostelium cells bind a secreted autocrine factor that represses cell proliferation Jonathan $\mathrm{MChoe}^{\dagger}$, Deenadayalan Bakthavatsalam${ }^{\dagger}$, Jonathan E Phillips and Richard H Gomer*
}

Address: Department of Biochemistry and Cell Biology, MS-140, Rice University, Houston, TX 77005-1892, USA

Email: Jonathan M Choe - jonathan_choe@hotmail.com; Deenadayalan Bakthavatsalam - db3@rice.edu; Jonathan E Phillips - jep1@rice.edu; Richard H Gomer* - richard@rice.edu

* Corresponding author †Equal contributors

Published: 2 February 2009

BMC Biochemistry 2009, 10:4 doi:10.| |86/|47|-209|-10-4
Received: 10 November 2008

Accepted: 2 February 2009

This article is available from: http://www.biomedcentral.com/|47I-209I//0/4

(C) 2009 Choe et al; licensee BioMed Central Ltd.

This is an Open Access article distributed under the terms of the Creative Commons Attribution License (http://creativecommons.org/licenses/by/2.0), which permits unrestricted use, distribution, and reproduction in any medium, provided the original work is properly cited.

\begin{abstract}
Background: Dictyostelium cells secrete the proteins AprA and CfaD. Cells lacking either AprA or CfaD proliferate faster than wild type, while AprA or CfaD overexpressor cells proliferate slowly, indicating that $A p r A$ and $C f a D$ are autocrine factors that repress proliferation. $C f a D$ interacts with AprA and requires the presence of AprA to slow proliferation. To determine if $C f a D$ is necessary for the ability of AprA to slow proliferation, whether AprA binds to cells, and if so whether the binding requires the presence of $\mathrm{CfaD}$, we examined the binding and effect on proliferation of recombinant AprA.

Results: We find that the extracellular accumulation of AprA increases with cell density and reaches a concentration of $0.3 \mu \mathrm{g} / \mathrm{ml}$ near a stationary cell density. When added to wild-type or aprA- cells, recombinant AprA (rAprA) significantly slows proliferation at $0.1 \mu \mathrm{g} / \mathrm{ml}$ and higher concentrations. From 4 to $64 \mu \mathrm{g} / \mathrm{ml}$, the effect of rAprA is at a plateau, slowing but not stopping proliferation. The proliferation-inhibiting activity of rAprA is roughly the same as that of native AprA in conditioned growth medium. Proliferating aprA- cells show saturable binding of rAprA to $92,000 \pm 1 \mathrm{I}, 000$ cell-surface receptors with a $K_{D}$ of $0.03 \pm 0.02 \mu \mathrm{g} / \mathrm{ml}$. There appears to be one class of binding site, and no apparent cooperativity. Native AprA inhibits the binding of rAprA to aprA- cells with a $K_{i}$ of $0.03 \mu \mathrm{g} / \mathrm{ml}$, suggesting that the binding kinetics of $r A p r A$ are similar to those of native AprA. The proliferation of cells lacking CrIA, a cAMP receptor-like protein, or cells lacking $\mathrm{CfaD}$ are not affected by rAprA. Surprisingly, both cell types still bind rAprA.
\end{abstract}

Conclusion: Together, the data suggest that AprA functions as an autocrine proliferationinhibiting factor by binding to cell surface receptors. Although AprA requires $\mathrm{CfaD}$ for activity, it does not require $\mathrm{CfaD}$ to bind to cells, suggesting the possibility that cells have an AprA receptor and a $\mathrm{CfaD}$ receptor, and activation of both receptors is required to slow proliferation. We previously found that $\mathrm{cr} / \mathrm{A}$ - cells are sensitive to $\mathrm{CfaD}$. Combined with the results presented here, this suggests that $\mathrm{CrIA}$ is not the $\mathrm{AprA}$ or $\mathrm{CfaD}$ receptor, and may be the receptor for an unknown third factor that is required for AprA and $C f a D$ activity. 


\section{Background}

Much remains to be understood about the mechanisms that regulate the size of a tissue. In some cases, it appears that secreted diffusible factors allow cells in a group to sense the size of the group [1,2]. As the number of cells secreting the factor increases, the concentration of the factor increases $[1,3]$. The cells sense the concentration of the factor, allowing them to sense the size of the group of cells. If the factor inhibits cell proliferation, the resulting negative feedback loop could effectively stop proliferation once a specific group or tissue size is reached. The group or tissue size would then be determined by how much factor the cells secrete, the diffusion properties of the factor, and how sensitive the cells are to the factor. There are a few examples of this sort of negative feedback loop. For example, myostatin is a protein secreted by muscle cells, and myostatin concentrations rise as the amount of muscle in the body increases [4]. Myostatin inhibits myoblast proliferation, which keeps the amount of muscle in the body at a relatively constant level [5]. Mutation or disruption of myostatin results in abnormally large muscles $[6,7]$. Another example of a negative feedback loop is thyroid size regulation. Thyroid cells secrete thyroid hormone, which inhibits the release of thyroid-stimulating hormone [8] from the pituitary. TSH functions to stimulate the growth of the thyroid. Thus, if the thyroid is damaged, thyroid hormone levels would fall, allowing more TSH release to promote thyroid growth [9]. A third example of a negative feedback loop involves regulation of adipose tissue within the human body. The leptin protein is secreted by adipocytes and signals the amount of adipose tissue present in the body [10,11]. High leptin levels signal to the body that appetite is satisfied, which decreases adipose tissue accumulation to complete the feedback loop.

There are many tissues where there is evidence for the existence of a secreted factor that inhibits cell proliferation to regulate tissue size, but the identity of the factor and its signal transduction pathway is unknown. For example, in mammals the liver has the ability to regenerate to the correct size if any portion of the liver is removed, and this appears to be mediated by an unknown factor that is secreted into the blood [12]. The spleen is another example of a tissue whose size appears to be negatively regulated by unknown secreted factors [13]. Identifying these factors and their signal transduction pathways will aid in our understanding of tissue size regulation.

Dictyostelium discoideum is an excellent model system to study secreted factors and the regulation of proliferation and group size. Dictyostelium is a haploid unicellular eukaryote that feeds on soil bacteria. There are several secreted signals whose extracellular concentration is sensed by Dictyostelium cells to, in turn, sense the local density or number of other Dictyostelium cells. When cells starve, they stop dividing and begin secreting an $80 \mathrm{kDa}$ glycoprotein called conditioned medium factor (CMF) [3,14-18]. As more and more cells in a population starve, the extracellular CMF concentration rises. When there is a high percentage of starved cells, as indicated to the cells by a high extracellular concentration of $\mathrm{CMF}$, the cells aggregate to form multicellular structures called fruiting bodies. The aggregating cells form dendritic streams flowing toward a common center. To regulate the size of the fruiting bodies, the streams break up into groups if there are too many cells in a stream [19]. Cells sense if there are too many cells in a stream by sensing the concentration of counting factor $(\mathrm{CF})$, a protein complex secreted by the aggregating cells [20-25].

$\mathrm{CF}$ is a $450 \mathrm{kDa}$ complex of at least 4 different proteins [20,23,26-28]. Partially purified CF contains 8 proteins, and we have been systematically identifying which are true CF components and which are contaminants. We identified two proteins, AprA and CfaD, in the partially purified CF preparation that are not CF components $[29,30]$. AprA and CfaD are components of a $150 \mathrm{kDa}$ complex and appear to bind to each other [30]. Disruption of either aprA or $c f a D$ results in cells that have an abnormally high proliferation rate, while overexpression of either protein slows proliferation [29,30]. Adding either $10 \mathrm{ng} / \mathrm{ml}$ immunoprecipitated native AprA (at the time, we had not found conditions to make recombinant AprA) [29], or $20 \mathrm{ng} / \mathrm{ml}$ or higher concentrations of recombinant $\mathrm{CfaD}[30]$, also slows cell proliferation. Recombinant CfaD however does not affect the proliferation of aprA-cells, suggesting that $\mathrm{CfaD}$ needs the presence of AprA to inhibit proliferation [30]. Neither AprA nor $\mathrm{CfaD}$ affect growth rates per nucleus (effectively the mass increase per hour of cells) [29,30]. Because of the finite amount of available nutrients in a given patch of soil, and because cells will soon starve after they reach a high cell density, we have hypothesized that the functions of AprA and $\mathrm{CfaD}$ are to slow proliferation without slowing growth as the cells reach high density, so that when the cells do starve, the cells will tend to be large and have a relatively large store of nutrients $[29,30]$.

While studying novel proteins with similarities to G-protein-coupled receptors, Raisley et al. [31] found that cells lacking CrlA, a putative a $\mathrm{G}$ protein coupled receptor, proliferate faster than wild type cells. Interestingly, we found that compared to its effect on wild-type cells, recombinant CfaD weakly inhibits the proliferation of $\mathrm{crlA}$ - cells [30]. This suggested that CrlA potentiates, but is not necessary for, CfaD signal transduction.

We recently found conditions in which we can express recombinant AprA (rAprA) [30]. In this report, we show that rAprA slows the proliferation of wild-type and aprAcells, but has no effect on $c f a D^{-}$or $c r l A^{-}$cells. However, 
rAprA binds to all four cell types, suggesting that $\mathrm{CfaD}$ and CrlA are necessary for AprA signal transduction, and that CrlA is a receptor for a different factor that regulates the ability of AprA to act as a chalone.

\section{Methods}

\section{Cell culture}

Wild-type Ax2, aprA- strain DB60T3-8 [29], cfaD- strain DB27C-1 [30], and crlA- strain JH557 [31] were cultured following Brock et al. [20] in HL5 medium (Formedium Ltd., Norwich, England). The growth of NC4 on bacteria was done as described in [30]. Calculation of doubling times was done as previously described [29].

Recombinant AprA and CfaD Expression and Purification Recombinant AprA (rAprA) and recombinant CfaD ( $\mathrm{rCfaD}$ ) were prepared following Bakthavatsalam et al. [30]. The concentrations of the purified proteins were determined as described in Gao et. al., [32].

\section{Quantification of secreted AprA}

The conditioned growth medium samples used for the AprA quantitation were aliquots of the samples we previously used to measure the accumulation of $\mathrm{CfaD}[30]$, allowing a direct comparison of the amount of AprA and the amount of $\mathrm{CfaD}$ secreted by cells. Samples of the conditioned growth media were run on $4-15 \%$ acrylamide gels (Biorad Laboratories, Hercules, CA) along with different known concentrations of rAprA. Western blots were stained with affinity-purified anti-AprA antibodies as described previously [29]. The AprA bands were then scanned and analyzed using ImageJ http:// rsb.info.nih.gov/ij/. The concentration of secreted AprA at each cell density was quantified by comparing against the known concentrations of rAprA.

\section{Proliferation inhibition by rAprA or conditioned growth medium}

To test the biological activity (cell proliferation inhibition activity) of rAprA or conditioned growth medium (pre- pared from wild-type cells grown to $1.2 \times 10^{7}$ cells $/ \mathrm{ml}$, where the measured rAprA concentration in the conditioned growth medium is $0.3 \mu \mathrm{g} / \mathrm{ml}$ ), cells were grown in HL5 media to a density of $2 \times 10^{6} \mathrm{cells} / \mathrm{ml}$, collected by centrifugation at $1,500 \times \mathrm{g}$ for 3 minutes, and resuspended in HL5 media to $5 \times 10^{5}$ cells $/ \mathrm{ml}$. Cells were then counted before and after 12 hours of incubation with rAprA (or an equal volume of buffer as a control) or conditioned growth medium (or an equal volume of HL5 as a control). A sigmoidal dose-response curve

Percent proliferation $=100-\left(\frac{\text { Max }}{1+10((\log (\text { EC50) })-(\log (\text { rAprA concentration })))}\right)$ was then fit to the data to obtain Max and EC50 using nonlinear regression with Prism (GraphPad software, San Diego, CA). In Table 1, Max is called 'proliferation as percent of control at high rAprA'. The units/ml of proliferation-inhibiting activity was defined as the fold dilution of added rAprA or conditioned growth medium that caused a $20 \%$ decrease in the density of cells after the 12-hour incubation. The units/ml was calculated using the Max and EC50 values obtained from the above curve fitting, and solving for rAprA concentration with percent proliferation set to 80. For a known concentration of AprA, the units/ml of activity could then be converted to units/ $\mu \mathrm{g}$.

\section{Determination of optimal binding time for rAprA}

To determine the saturation binding time of rAprA, cells were grown to a density of $2 \times 10^{6} \mathrm{cells} / \mathrm{ml}$. Cells were collected by centrifugation at $1,500 \times \mathrm{g}$ for 3 minutes. Cells were briefly washed twice in ice cold HL5 and were resuspended in ice cold HL5 to a final concentration of $1.0 \times$ $10^{7}$ cells $/ \mathrm{ml}$ and kept on ice. $0.5 \mu \mathrm{l}$ of $300 \mu \mathrm{g} / \mathrm{ml} \mathrm{rAprA}$ was added to $500 \mu \mathrm{l}$ of cells, and this was gently mixed on a rotator at $4{ }^{\circ} \mathrm{C}$ for $0,1,2,5,10$, or 30 minutes. Cells were collected after the indicated times by centrifugation at $10,000 \times \mathrm{g}$ for 30 seconds and washed briefly in $500 \mu \mathrm{l}$ of ice cold HL5. Following the wash, the cells were resuspended in $100 \mu \mathrm{l}$ of SDS sample buffer and heated at

Table I: rAprA and wild-type conditioned growth medium slow the proliferation of wild-type (WT) and aprA- cells.

\begin{tabular}{|c|c|c|c|c|c|}
\hline \multirow[b]{2}{*}{ Cell type } & \multicolumn{2}{|r|}{ rAprA } & \multicolumn{3}{|c|}{ WT conditioned growth medium (CGM) } \\
\hline & Activity, units/ $\mu \mathrm{g}$ & $\begin{array}{l}\text { Proliferation as percent } \\
\text { of control at high rAprA }\end{array}$ & Activity, units/ml & $\begin{array}{l}\text { Proliferation as percent } \\
\text { of control at high CGM }\end{array}$ & Activity, units/ $\mu$ g AprA \\
\hline WT & $3.7 \pm 0.9$ & $71 \pm 1$ & $1.5 \pm 0.5$ & $64 \pm 8$ & $4.9 \pm 1.7$ \\
\hline aprA- & $10.7 \pm 2.8$ & $70 \pm 1$ & $1.4 \pm 0.5$ & $60 \pm 6$ & $4.5 \pm 1.7$ \\
\hline$c f a D^{-}$ & $0 \pm 0$ & $97 \pm 1$ & ND & ND & ND \\
\hline crlA- & $0 \pm 0$ & $97 \pm 1$ & ND & ND & ND \\
\hline
\end{tabular}

Cells of the indicated strain were grown in the presence of different concentrations of rAprA, and cells were counted after 12 hours. After fitting sigmoidal dose response curves (Figure 2), the activity of rAprA and the proliferation as a percent of control at high concentrations of rAprA were calculated. Similar fits were done for cells grown in different dilutions of wild-type conditioned growth medium (Figure 3). The activity of the AprA in conditioned growth medium was calculated using the observed AprA concentration of $0.3 \mu \mathrm{g} / \mathrm{ml}$. All values are mean \pm SEM from 3 independent experiments. ND indicates not determined. 
$95^{\circ} \mathrm{C}$ before loading $10 \mu \mathrm{l}$ onto a $4-15 \%$ gel (Biorad). Different concentrations of rAprA were used as a standard on the same gel, and proteins were transferred onto a PVDF membrane (Immobilin-P, Millipore corporation, Bedford, MA). A duplicate gel was stained with Coomassie to verify that there were roughly equal amounts of protein in each sample. To detect rAprA (which contains a myc tag), the blots were stained with a 1:10,000 dilution of anti-myc antibodies (Bethyl laboratories, Montogomery, TX) in $25 \mathrm{mM}$ Tris/HCl pH 7.4, $150 \mathrm{mM} \mathrm{NaCl} / 0.1 \%$ Tween-20 for 1 hour, and subsequent steps for Western blotting were done following [29]. The rAprA bands on the autoradiograph were scanned and the binding experiment intensities were compared against the standards to determine the concentration of bound rAprA. An association binding curve

$$
\text { Bound rAprA = Bmax }\left(1-e^{-k t}\right)
$$

where $t$ is time was then fit to the data using Prism.

\section{Steady state binding}

A binding assay was performed as described above except that the cells were incubated with different concentrations of rAprA for 10 minutes at $4{ }^{\circ} \mathrm{C}$. One- and two- site binding curves with and without cooperative binding were then fit to the data using Prism.

\section{Competitive binding}

For competitive binding assays, wild-type conditioned growth medium (CGM) was prepared as described previously [33]. The concentration of AprA in the conditioned medium was measured as described above. A binding assay was performed as described above with the exception that aprA-cells were used, and were resuspended in pre-chilled mixtures of HL5 medium and wild type conditioned growth medium before adding $150 \mathrm{ng} / \mathrm{ml}$ of rAprA. After 10 minutes of incubation, the amount of bound rAprA was determined as described above. A sigmoidal dose-response curve

Bound $\mathrm{rAprA}=\mathrm{BT}-\left(\frac{\mathrm{BT}}{1+10((\log (\mathrm{IC} 50))-(\log (\text { native AprA concentration })))}\right)$

where BT is the maximal rAprA binding in the competition assay and IC50 is the concentration of native AprA that causes 50\% inhibition of the AprA binding, was then fit to the data using nonlinear regression with Prism. The $\mathrm{K}_{\mathrm{i}}$ for the binding inhibition was then calculated from the IC50 using the equation of Cheng and Prusoff [34].

\section{Results}

\section{Recombinant AprA is bioactive}

AprA is a secreted signal in Dictyostelium cells that slows cell proliferation [29]. To determine the extracellular con- centration of AprA, we expressed and purified recombinant AprA (rAprA) for use as a reference standard (Figure 1A). The rAprA appeared as a single band at 60 $\mathrm{kDa}$, which roughly corresponds to the sum of the predicted molecular mass of the his/myc tag on the rAprA $(5.3 \mathrm{kD})$ and the predicted mass of the secreted portion of the AprA polypeptide backbone $(53.1 \mathrm{kDa})$. Since the observed mass of the secreted portion of native AprA is 60 $\mathrm{kDa}[29]$, the observed mass of rAprA suggests that the secreted native AprA contains 5-7 kDa of posttranslational modification, presumably glycosylation. Western blots of conditioned growth medium electrophoresed alongside known quantities of rAprA were stained with affinity-purified anti-AprA antibodies. We observed an increase in the accumulation of extracellular AprA with cell density during the growth of wild-type cultures (Figure $1 \mathrm{~B}$ ). As the cultures reached saturation at $\sim 1.2 \times 10^{7}$ cells $/ \mathrm{ml}$, the AprA concentration rose to $0.3 \mu \mathrm{g} / \mathrm{ml}$. This corresponds to an accumulation of $2.5 \times 10^{-8} \mu \mathrm{g} / \mathrm{cell}$. Similar assays showed that at a density of $2 \times 10^{6}$ cells $/ \mathrm{ml}$, both $c f a D^{-}$and $c r l A^{-}$cells had accumulated $0.6 \pm 0.1 \mu \mathrm{g} / \mathrm{ml}$ of extracellular AprA (data not shown), indicating that loss of $\mathrm{CfaD}$ or CrlA causes cells to accumulate, compared to wild-type cells, roughly ten times more extracellular AprA.

It took 16 hours for wild-type cultures to proliferate from $0.5 \times 10^{6} \mathrm{cells} / \mathrm{ml}$ to $1.3 \times 10^{6} \mathrm{cells} / \mathrm{ml}$, and during this time the extracellular AprA concentration increased by $0.021 \pm 0.001 \mu \mathrm{g} / \mathrm{ml}($ mean $\pm \mathrm{SEM}, \mathrm{n}=3)$. Assuming that
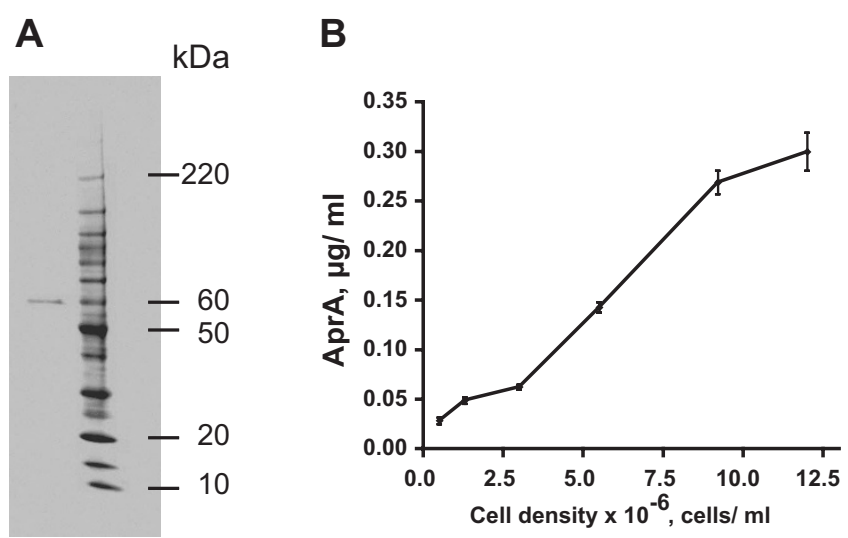

\section{Figure I}

The concentration of extracellular AprA increases with cell density. A) An SDS-polyacrylamide gel of recombinant AprA (left lane) and molecular mass standards (right lane) was stained with Coommassie.B) Using different concentrations or recombinant AprA to make a standard curve, Western blots were used to determine the extracellular concentration of AprA as a function of cell density. Values are mean $\pm \operatorname{SEM}(n=3)$. The absence of error bars indicates that the error was smaller than the plot symbol. 
during log-phase growth the cell density $\rho=\mathrm{N}_{\mathrm{o}} \mathrm{e}^{\mathrm{kt}}$, we see that with $\mathrm{N}_{\mathrm{o}}=0.5 \times 10^{6} \mathrm{cells} / \mathrm{ml}, \mathrm{k}=0.060 /$ hour. Assuming a constant AprA accumulation rate/cell/hour $=\mathrm{X}$, then

$$
21 \mathrm{ng} / \mathrm{ml}=\int_{0}^{16} X \rho d t
$$

Solving for $\mathrm{X}$, we find that between $0.5 \times 10^{6}$ and $1.3 \times 10^{6}$ cells $/ \mathrm{ml}$, the extracellular AprA accumulation rate is $1.6 \times$ $10^{-9} \mu \mathrm{g} /$ cell/hour, or $2.6 \times 10^{-11} \mu \mathrm{g} / \mathrm{cell} / \mathrm{minute}$, or 260 molecules of AprA/cell/minute. Similar calculations were done for the other cell density ranges shown in Figure 1B, as well as for the extracellular $\mathrm{CfaD}$ concentrations shown in Figure 3 of [30]. As shown in Table 2, with the assumption that there is no breakdown of extracellular AprA or $\mathrm{CfaD}$, the accumulation rate of extracellular AprA per cell per hour fluctuates as the cell density in the population increases, with a general tend of decreasing as the cells approach saturation density. Conversely, the accumulation rate of extracellular $\mathrm{CfaD}$ per cell per hour increases as the cell density in the population increases (Table 2).

In the wild, Dictyostelium cells grow on soil surfaces. The parental strain used in these studies is an axenic strain derived from an isolate from North Carolina called NC4 [35]. We found that when NC4 strains grow on lawns of bacteria on agar plates, they secrete both CfaD and AprA, and that NC4 cells growing on bacteria accumulate approximately 4 times more CfaD per cell than Ax 2 cells at $1.2 \times 10^{7}$ cells $/ \mathrm{ml}$ in shaking culture [30]. Using rAprA to generate a standard curve, we found that when there are $3 \times 10^{7} \mathrm{NC} 4$ cells on an agar plate, the agar contains $2.0 \pm$ $0.1 \mu \mathrm{g}$ of AprA (mean $\pm \mathrm{SEM}, \mathrm{n}=3$ ). This corresponds to an accumulation of $6.6 \times 10^{-8} \mu \mathrm{g} /$ cell, which is approximately 2.6 times higher than the accumulation for Ax2 cells at stationary phase. The data thus suggest that in the natural environment, cells accumulate somewhat more AprA and $\mathrm{CfaD}$ than axenic cells in shaking culture.
We previously observed that immunoprecipated native AprA slows the proliferation of wild-type and aprA-cells [29]. To determine if any eukaryote-specific posttranslational modification such as glycosylation is part of the AprA active site, we added rAprA to cells. After 12 hours, rAprA at concentrations at and above $0.1 \mu \mathrm{g} / \mathrm{ml}$ significantly slowed the proliferation of wild-type and aprA-cells (Figure 2A and Table 1). A recombinant version of the human serum protein Serum Amyloid P, made with the same expression vector in the same bacterial cell line, as well as bovine serum albumin, had no effect on cell proliferation (data not shown). Even at high concentrations $(64 \mu \mathrm{g} / \mathrm{ml})$, rAprA was only able to slow the proliferation of wild-type and aprA-cells rather than completely arrest their proliferation (Figure 2A). The doubling times we observed for wild-type and aprA-cells were 12.7 and 9.1 hours respectively, essentially identical to what we previously observed [29]. At $1 \mu \mathrm{g} / \mathrm{ml} \mathrm{rAprA}$, the doubling time for wild-type cells was 19.3 hours, and at $4 \mu \mathrm{g} / \mathrm{ml}$ the doubling time was 24.5 hours, similar to the 23.3 hour doubling time we observed for cells overexpressing AprA [29]. Interestingly, rAprA had essentially no ability to slow the proliferation of $c r l A^{-}$or $c f a D^{-}$cells. These results demonstrate that rAprA is bioactive, that if AprA is glycosylated, the glycosylation is not essential for bioactivity, and suggest that CrlA and $\mathrm{CfaD}$ are required for the ability of rAprA to slow cell proliferation.

\section{CfaD and AprA potentiate each other's ability to slow proliferation}

Like AprA, CfaD is a protein secreted by growing Dictyostelium cells that slows cell proliferation [30]. CfaD appears to bind to AprA and requires AprA for bioactivity. To determine if $\mathrm{rCfaD}$ potentiates the activity of rAprA, we added mixtures of rAprA and rCfaD to cells. CfaD accumulates to $\sim 0.08 \mu \mathrm{g} / \mathrm{ml}$ when cells are at $1.2 \times 10^{7}$ cells/ $\mathrm{ml}$, while AprA accumulates to $\sim 0.3 \mu \mathrm{g} / \mathrm{ml}$ at this density. As a rough comparison, we thus added $2: 1 \mathrm{w} / \mathrm{w}$ mixtures of rAprA:rCfaD to wild type cells (Figure 2B). A fit of a sigmoidal dose response curve indicated that at high concentrations, the mixture is able to slow proliferation to $72 \pm$ $3 \%$ of control (mean \pm SEM, $\mathrm{n}=3$ ). This is not significantly different from the amount that high concentrations

Table 2: The accumulation of AprA and $\mathrm{CfaD}$ as a function of cell density.

\begin{tabular}{ccccc}
\hline & \multicolumn{2}{c}{ AprA accumulation } & \multicolumn{2}{c}{ CfaD accumulation } \\
\cline { 2 - 5 } Density range, $10^{6}$ cells/ml & $10^{-10} \mu$ g/cell/hour & Molecules/minute & $10-10 \mu$ g/cell/hour & Molecules/minute \\
\hline $\mathbf{0 . 5}-1.3$ & $15.4 \pm 0.6$ & $260 \pm 10$ & $<0.004$ & $<1$ \\
$1.3-3.0$ & $2.9 \pm 0.1$ & $49 \pm 2$ & $0.7 \pm 0.1$ & $11 \pm 2$ \\
$\mathbf{3 . 0}-\mathbf{5 . 5}$ & $8.5 \pm 0.7$ & $140 \pm 10$ & $1.0 \pm 0.2$ & $17 \pm 3$ \\
$\mathbf{5 . 5}-\mathbf{9 . 2}$ & $7.3 \pm 0.4$ & $120 \pm 7$ & $1.2 \pm 0.1$ & $19 \pm 2$ \\
$\mathbf{9 . 2}-\mathbf{1 2}$ & $1.3 \pm 0.3$ & $22 \pm 5$ & $3.6 \pm 0.2$ & $59 \pm 4$
\end{tabular}

The accumulation values are derived from the AprA quantitation in Figure I and from the CfaD quantitation in Figure 3 of [30]; both figures used the same set of samples for quantitation. Values are mean \pm SEM from 3 separate experiments. 

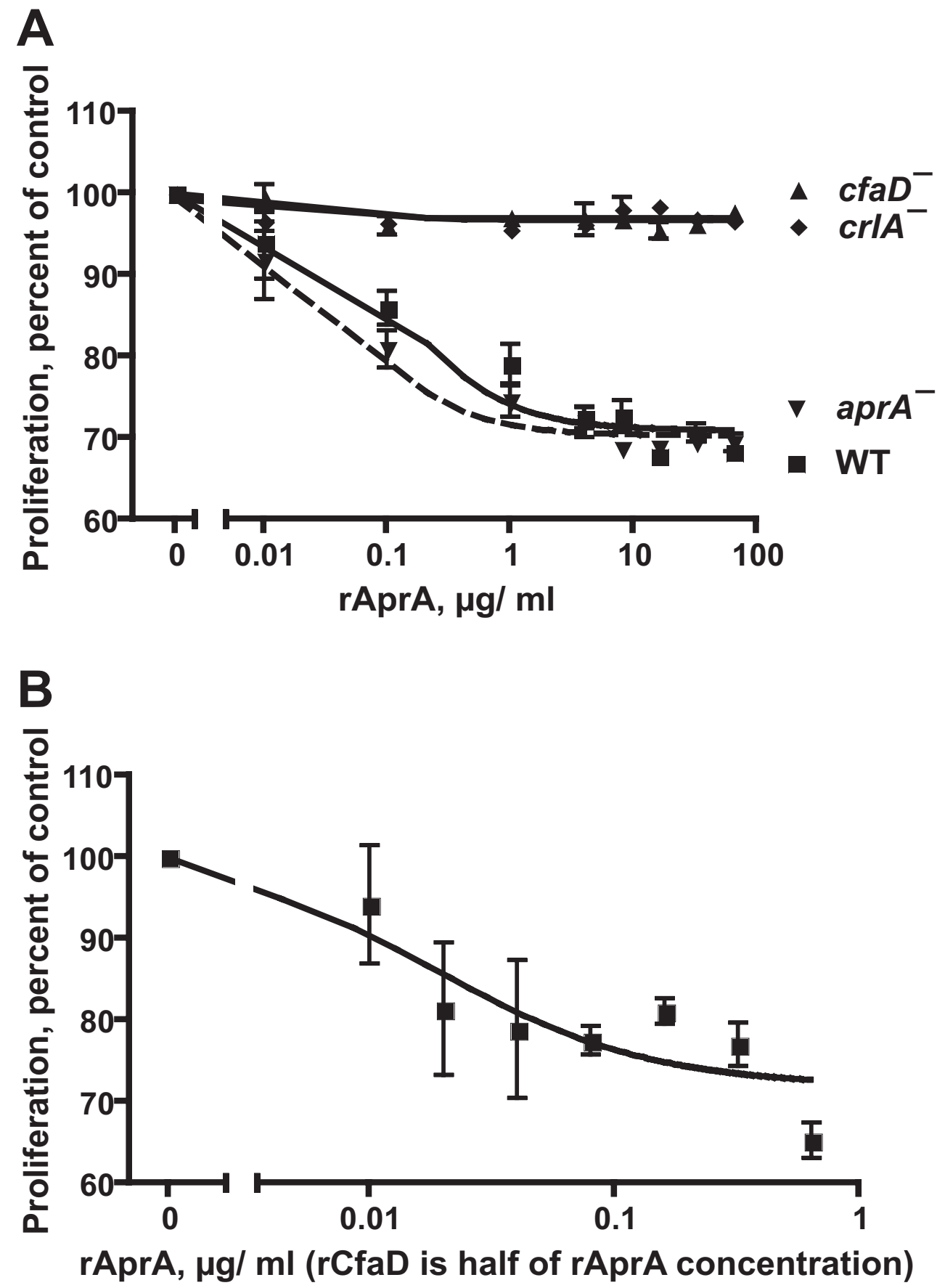

Figure 2

rAprA slows cell proliferation. A) Different concentrations of rAprA were added to the indicated cell types, and after 12 hours cells were collected and counted. WT is wild-type. Values are mean $\pm \operatorname{SEM}(n=3)$. The absence of error bars indicates that the error was smaller than the plot symbol. The lines are sigmoidal dose response curve fits to the data; the dashed line is the fit to aprA- The inhibition of wild type and aprA- proliferation is significant with $\mathrm{p}<0.0 \mathrm{l}$ at $0.1 \mu \mathrm{g} / \mathrm{ml}$ and higher rAprA concentrations ( I-way ANOVA, Dunnett's test). B) A 2:I mixture of $r A p r A$ and $r C f a D$ was added to wild-type cells as in $\mathbf{A}$ above, so that at, for instance, $0.32 \mu \mathrm{g} / \mathrm{ml} \mathrm{rAprA}$ there was an additional $0.16 \mu \mathrm{g} / \mathrm{ml} \mathrm{rCfaD}$. Values are mean \pm SEM $(\mathrm{n}=3)$. The line is a sigmoidal dose response curve fit to the data. The inhibition of wild type proliferation is significant with $p<0.05$ at $0.02 \mu \mathrm{g} /$ $\mathrm{ml} \mathrm{rAprA} / 0.01 \mu \mathrm{g} / \mathrm{ml} \mathrm{rCfaD}$ and higher concentrations ( $\mathrm{t}$ test). 
of rAprA or rCfaD can slow proliferation (Table 1 and [30]). rAprA slows proliferation to $80 \%$ of control at $\sim 0.27 \mu \mathrm{g} / \mathrm{ml}$ (Figure 2A and Table 1), while $\mathrm{rCfaD}$ slows proliferation to $80 \%$ of control at $0.05 \mu \mathrm{g} / \mathrm{ml}$ [30]. The mixture slows proliferation to $80 \%$ of control at $0.045 \mu \mathrm{g} /$ $\mathrm{ml} \mathrm{rAprA} / 0.022 \mu \mathrm{g} / \mathrm{ml} \mathrm{rCfaD}$ (Figure 2B). This suggests that the presence of $\mathrm{CfaD}$ decreases the concentration of AprA needed to slow proliferation, and vice versa.

The conditioned growth medium from wild-type cells slows aprA- cell proliferation, whereas conditioned growth medium from $a p r A^{-}$cells lacks this activity, indicating that AprA is a key component of the proliferation-inhibiting activity in wild-type conditioned growth medium [29]. To compare the proliferation-inhibiting activity of recombinant AprA to the AprA-associated activity in conditioned growth medium, cells were grown in different dilutions of conditioned growth medium collected from wild-type cells at $1.2 \times 10^{7}$ cells/ml. After 12 hours, wildtype conditioned growth medium at concentrations above $30 \%$ significantly slowed the proliferation of wild type and aprA-cells (Figure 3 and Table 1). Using the observed AprA concentration in conditioned growth medium (collected from wild-type cells at $1.2 \times 10^{7}$ cells/ $\mathrm{ml}$ ) of $0.3 \mu \mathrm{g} / \mathrm{ml}$ (Figure 1), the AprA activity, as measured in units/ $\mu \mathrm{g}$ of the AprA in wild-type conditioned growth

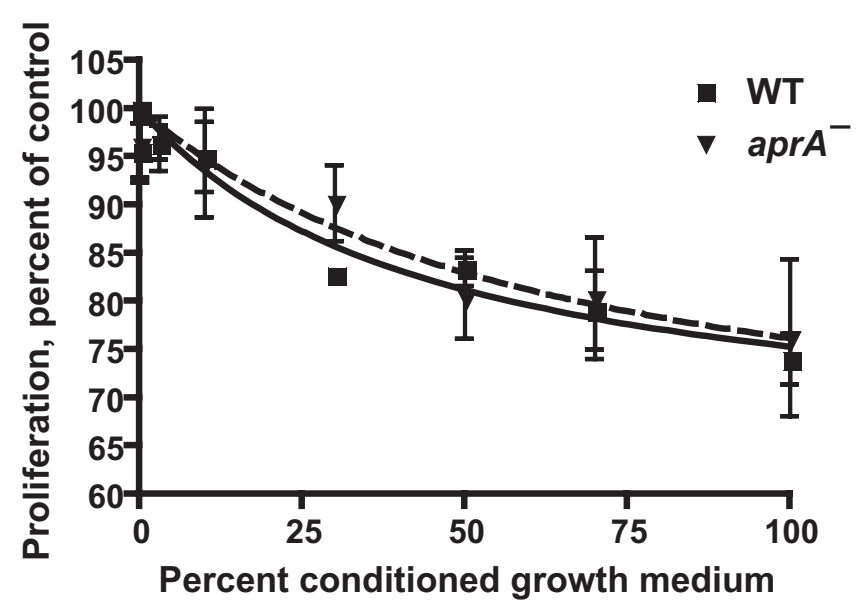

Figure 3

Wild-type conditioned growth medium slows cell proliferation. Conditioned growth medium was collected and diluted with fresh growth medium to the indicated concentrations. Wild-type (WT) and aprA- cells were then grown in the mixed media, and cells were counted after 12 hours. Values are mean $\pm \operatorname{SEM}(n=3)$. The absence of error bars indicates that the error was smaller than the plot symbol. Lines are curve fits of a sigmoidal dose response curve; the dashed line is the fit to aprA-. The inhibition of WT and aprAproliferation is significant with $p<0.05$ at $30 \%$ and higher conditioned growth medium concentrations ( I-way ANOVA, Dunnett's test). medium, on wild-type or aprA-cells was roughly similar to the activity of rAprA on wild-type cells; the differences were not statistically significant ( $\mathrm{p}>0.05,1$-way ANOVA, Tukey's test) (Table 1). However, at high concentrations, the wild-type conditioned growth medium caused a somewhat greater inhibition of proliferation than high concentrations of rAprA (Figures 2 and 3 and Table 1). Together, the results suggest that rAprA has roughly the same bioactivity as native AprA, but that there may be additional factors in conditioned growth medium that slow cell proliferation.

\section{Recombinant AprA binds to Dictyostelium cells}

To determine if AprA is sensed by cell surface receptors, we examined the binding of rAprA to cells. The binding assays were done in HL5 growth medium, as we previously observed that we could measure binding of CMF to cells in this medium [16]. After trying a variety of binding times and concentrations to establish rough time and concentration conditions for the assays (Figure 4 and data not shown), the time course of rAprA binding was examined to establish steady state conditions for further binding assays. The amount of rAprA bound to cells reached near steady state levels by 10 minutes (Figure 5). Interestingly, even though rAprA was unable to inhibit the proliferation of $c f a D^{-}$and $c r l A^{-}$cells, rAprA bound to these cells. Although there appeared to be differences in the binding rates, the difference in the binding time constant $\mathrm{k}$ between all pairs of cell types was not significant ( $p>$ 0.05, 1-way ANOVA, Tukey's test). In addition, although it appeared that there were differences in the amount of rAprA bound at 10 and 30 minutes to the different cell types, the difference between all pairs of cell types was not significant ( $p>0.05,1$-way ANOVA, Tukey's test).

A key property of binding is that it is saturable. To examine whether the binding of rAprA to cells is saturable, cells were incubated with different concentrations of rAprA and the amount of bound rAprA was measured after 10 minutes. For wild-type and $\mathrm{crlA}$-cells, the binding of rAprA appeared to saturate above a free rAprA concentration of $0.4 \mu \mathrm{g} / \mathrm{ml}$ (Figure 6 and Table 3). There appeared to be a higher level of binding to aprA- and $c f a D^{-}$cells, the binding appeared to roughly saturate, and there appeared to be a lower $K_{D}$ for binding to these two cell lines. The binding appeared to be specific, as competition with 10 $\mu \mathrm{g} / \mathrm{ml}$ of BSA had no discernable effect on binding (data not shown). For all four cell lines, binding curves were fit using nonlinear regression with an equation for one-site binding. F-tests comparing these fits to fits with a two-site binding model, or fits to binding models with a variable Hill coefficient, indicated that for each of the four cell lines there did not appear to be two classes of binding sites or cooperative binding; the Hill coefficient for binding to 
Standards

$0.5 \quad 2 \quad 4 \quad 6$

Added to cells

$\begin{array}{llllllllll}0 & 20 & 40 & 80 & 120 & 160 & 200 & 400 & 800 & 1600 \\ n g\end{array}$

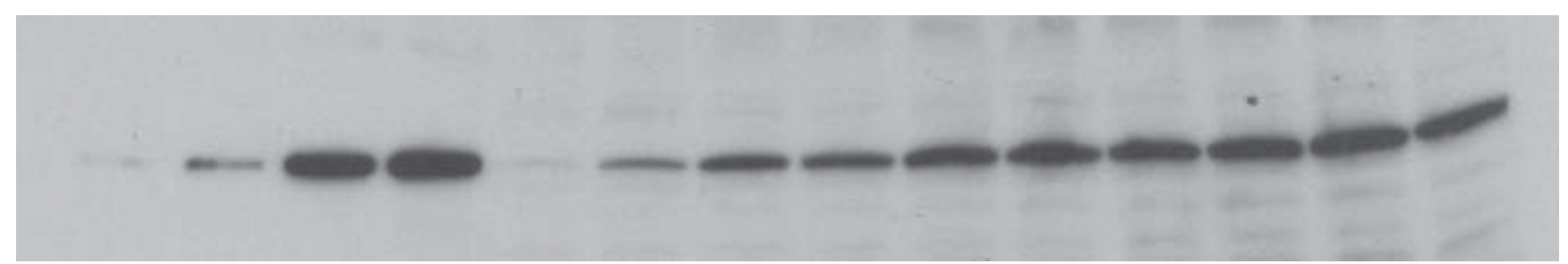

\section{Anti-Myc}

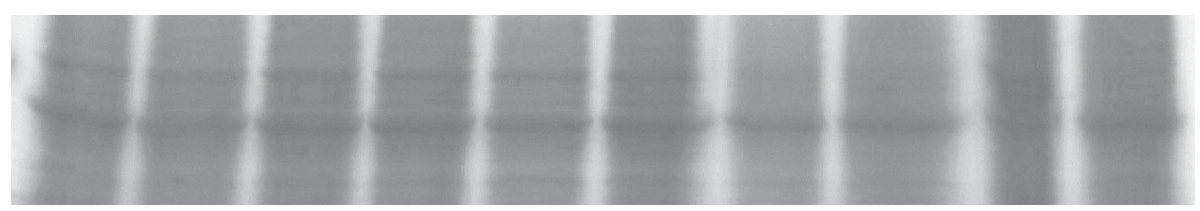

\section{Loading control (Coommassie stained gel)}

\section{Figure 4}

Binding of rAprA to cells. For a rAprA binding assay, wild-type cells were incubated for 10 minutes with the indicated concentrations ("Added to cells" in $\mathrm{ng} / \mathrm{ml}$ ) of myc-tagged rAprA. The cells were then washed to remove unbound rAprA, and were solubilized in SDS sample buffer. A western blot of the solubilized cells electrophoresed alongside different amounts of myc-tagged rAprA ("Standards") was stained with anti-myc antibodies (upper panel) while a duplicate gel of the cell samples was stained with Coomassie (lower panel). The heavy band in the Coomassie-stained samples is actin.

wild-type cells was 1.0. Taken together, the data suggests that rAprA shows saturable binding to cells.

To compare the cell surface binding of rAprA to that of native AprA, we measured the inhibition of rAprA binding to aprA- cells by different concentrations of native AprA, using wild-type conditioned growth medium from cells at $1.2 \times 10^{7}$ cells $/ \mathrm{ml}$ as a source of native AprA. As the concentration of wild-type conditioned growth medium in the binding assay increased, the amount of rAprA binding to aprA- cells decreased (Figure 7). Using the equation of Cheng and Prusoff [34] and the observed AprA concentration of $0.3 \mu \mathrm{g} / \mathrm{ml}$ in wild type conditioned growth medium from cells at $1.2 \times 10^{7}$ cells $/ \mathrm{ml}$, we found that native AprA had an inhibition constant $\left(\mathrm{K}_{\mathrm{i}}\right)$ of $0.03 \mu \mathrm{g} / \mathrm{ml}$, which is similar to the $0.03 \mu \mathrm{g} / \mathrm{ml} \mathrm{K}_{\mathrm{D}}$ for the binding of rAprA to aprA- cells. Taken together, the data suggest that the binding affinity of rAprA to aprA- cells is roughly similar to that of native AprA.

\section{Discussion}

Dictyostelium cells appear to regulate cell proliferation by secreting and sensing AprA and CfaD [29,30]. We found here that at $21^{\circ} \mathrm{C}$, wild-type cells accumulate 260 molecules/cell/minute of extracellular AprA at low cell densities, and this decreases to 22 molecules/cell/minute as cells approach saturation density. Conversely, the CfaD accumulation rate appears to increase from less than 1 molecule/cell/minute at low density to 59 molecules/cell/ minute near saturation density. These changes in accumulation rates as the cell density in a culture increases may be due to changes in nutrient or waste product levels, or changes in levels of signals such as AprA and CfaD. These accumulation rates are in the range of the 12 molecules/ cell/minute for CMF [36], the 60 molecules/cell/minute for the accumulation of CF by wild-type cells [32], and the 250 molecules/cell/minute we observed for the accumulation of CF by smlA- cells [20]. 


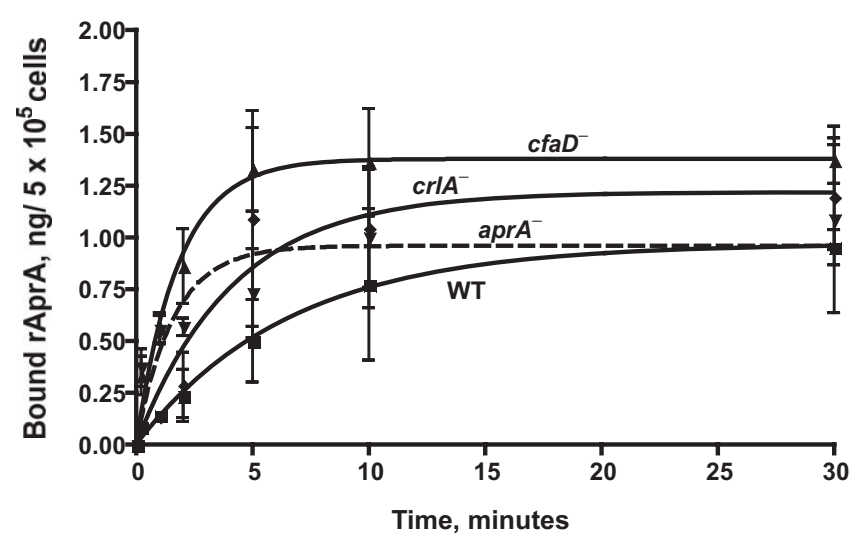

Figure 5

Time course of rAprA binding to cells. Cells of the indicated strains (WT is wild-type) were incubated with I50 ng/ $\mathrm{ml}$ of rAprA for the indicated times at $4^{\circ} \mathrm{C}$. Cells were collected and the bound myc-tagged rAprA was quantitated by western blots (staining for the myc tag), using known amounts of rAprA as standards. The plot symbols are the same as those in Figure 2. Values are mean $\pm \operatorname{SEM}(n=3)$. Lines are curve fits of an association binding curve; the dashed line is the fit to aprA-.

Using the AprA secretion rate of 49 molecules/cell/minute for cells harvested at $2 \times 10^{6}$ cells $/ \mathrm{ml}$, we can calculate that, if the binding assays had been done at $21^{\circ} \mathrm{C}$, in our 10-minute binding assays wild-type cells would accumulate $4.9 \times 10^{-4} \mu \mathrm{g} / \mathrm{ml}$ of AprA. This is less than the lowest

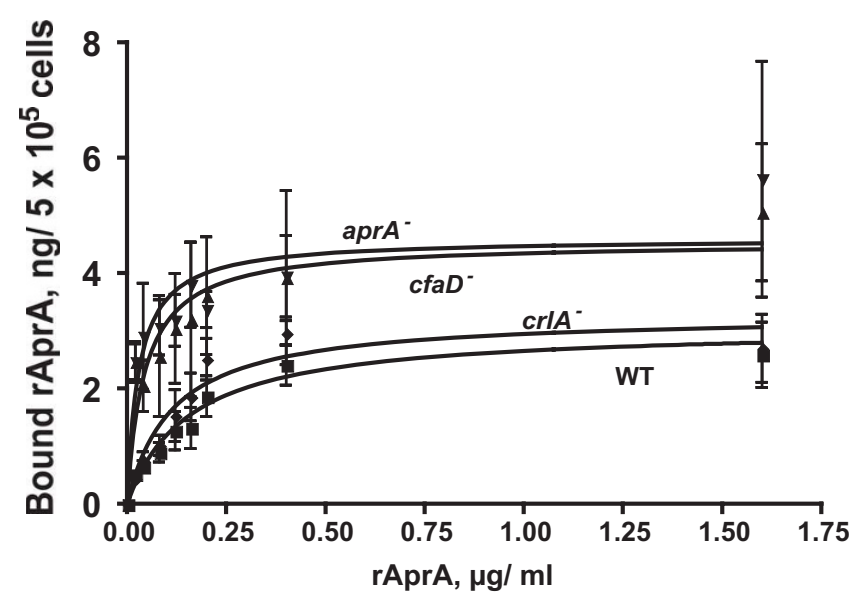

\section{Figure 6}

Cells bind physiological concentrations of rAprA. Cells of the indicated strains (WT is wild-type) were incubated with different concentrations of rAprA. After 10 minutes, cells were collected and the bound rAprA was measured as in Figure 5. The plot symbols are the same as in Figure 2. Values are mean $\pm \operatorname{SEM}(n=3)$. For the $60 \mathrm{kDa}$ rAprA, a bound rAprA value of $1.0 \mathrm{ng} / 5 \times 10^{5}$ cells is equivalent to $2.0 \times 10^{4}$ molecules/cell. The lines are curve fits to a one-site binding model with no cooperative binding. concentration of rAprA used for the binding curves (other than the buffer control) and well below the measured $\mathrm{K}_{\mathrm{D}}$ 's (Table 3). We saw that, at the density that we harvested cells for the binding assays, $c r l A^{-}$and $c f a D^{-}$cells accumulated roughly 10 times more AprA than wild-type cells. This could be due to an increased AprA secretion rate or a decreased AprA degradation rate, or some combination of the two. Assuming a ten-times higher AprA secretion rate, $c r l A^{-}$and $c f a D^{-}$cells would accumulate $4.9 \times 10^{-3} \mu \mathrm{g} / \mathrm{ml}$ of AprA in the 10-minute binding assays. This is still below the observed $\mathrm{K}_{\mathrm{D}}$ 's. At $4{ }^{\circ} \mathrm{C}$ (the condition for the binding assays), the secretion rate will be even lower than at $21^{\circ} \mathrm{C}$, so the amount of AprA secreted by cells during the binding assay should not have strongly interfered with the binding assay results.

Cells overexpressing Apra or CfaD still proliferate, albeit slowly, and recombinant $\mathrm{CfaD}$ slows but does not stop the proliferation of cells [29,30]. Like CfaD, rAprA slows but does not stop cell proliferation, even when combined with recombinant $\mathrm{CfaD}$ at concentrations three times higher than seen in the conditioned growth medium of stationary phase cells (Figures 2A and 2B). One can imagine that in the wild, a Dictyostelium cell might find itself in a small enclosed space where secreted factors might build up to very high concentrations, and having high concentrations of a chalone completely stop proliferation would be disadvantageous. The observed response of cells to AprA and CfaD (slowing but not stopping proliferation) thus might allow cells to increase their mass and protein content as they reach a high density, without incurring the risk of unnecessarily stopping proliferation under some conditions.

The response of wild-type and aprA-cells is nonlinear: it takes approximately $0.01 \mu \mathrm{g} / \mathrm{ml}$ rAprA to decrease the cell density at 12 hours by $10 \%$, approximately $0.1 \mu \mathrm{g} / \mathrm{ml}$ to decrease the density by an additional $10 \%$, and more than $1 \mu \mathrm{g} / \mathrm{ml}$ to cause a further $\sim 10 \%$ decrease (Figure $2 \mathrm{~A}$ ). rAprA appeared to have a higher activity (in units/ $\mu \mathrm{g}$ ) when added to $a p r A^{-}$cells compared to its activity on wildtype cells (Figure 2A and Table 1). A qualitative explanation for this is that wild-type cells are accumulating extracellular AprA while aprA- cells are not, so in the proliferation assay the wild-type cells are effectively starting at a higher extracellular AprA concentration compared to the aprA-cells. Since our definition of a unit of AprA activity is the inverse of the amount of AprA needed to inhibit proliferation by $20 \%$ at 12 hours, and given the nonlinear response of cells to AprA, it would thus take more AprA to slow wild-type cells by an additional $20 \%$ compared to the amount of AprA needed to slow aprAcells by $20 \%$. This would then predict that AprA would appear to have a lower activity on wild-type cells com- 
Table 3: The measured $K_{D}$ and Bmax for the binding of rAprA to vegetative cells.

\begin{tabular}{ccccc}
\hline Cell type & $\mathbf{K}_{\mathbf{D}}, \mu \mathbf{g} / \mathbf{m l}$ & $\mathbf{K}_{\mathbf{D}}, \mathbf{n M}$ & Bmax, $\mathbf{n g} / \mathbf{5} \times \mathbf{~} \mathbf{0}^{\mathbf{5}}$ cells & Bmax, molecules/cell \\
\hline WT & $0.16 \pm 0.05$ & $2.6 \pm 0.8$ & $3.1 \pm 0.4$ & $62,000 \pm 8,000$ \\
aprA- & $0.03 \pm 0.02$ & $0.5 \pm 0.3$ & $4.6 \pm 0.6$ & $92,000 \pm 11,000$ \\
cfaD- & $0.04 \pm 0.03$ & $0.7 \pm 0.5$ & $4.5 \pm 0.7$ & $91,000 \pm 14,000$ \\
crlA- & $0.11 \pm 0.04$ & $1.9 \pm 0.6$ & $3.3 \pm 0.3$ & $66,000 \pm 7,000$
\end{tabular}

For each cell line, the $K_{D}$ in $\mu g / m l$ and the $B m a x$ in $n g / 5 \times 10^{5}$ cells was obtained from the curve fits in Figure 6 . The $K_{D}$ in $n M$ and $B m a x$ in molecules/cell were calculated using a molecular mass of $60 \mathrm{kDa}$ for rAprA. All values are mean \pm SEM, $n=3$. For both the the K $\mathrm{K}_{\mathrm{D}} \mathrm{s}$ and the Bmax's, the difference between any two cell lines is not significant ( $P>0.05,1$-way ANOVA, using either Tukey's or Bonferroni's test).

pared to its activity on aprA- cells, which is what we observed.

Immunoprecipitated native extracellular AprA at $10 \mathrm{ng} /$ $\mathrm{ml}$ significantly slowed the proliferation of wild-type and aprA- cells [29], whereas higher concentrations of rAprA are needed to significantly slow proliferation. Native AprA has a higher molecular mass than recombinant AprA and thus appears to have some posttranslational modification, presumably glycosylation. This difference in posttranslational modifications may be the explanation for why native AprA appears to be more potent than recombinant AprA.

rAprA and rCfaD appear to potentiate each other's ability to inhibit proliferation (Figures $2 \mathrm{~A}$ and $2 \mathrm{~B}$ and Table 1). However, conditioned growth medium, which contains

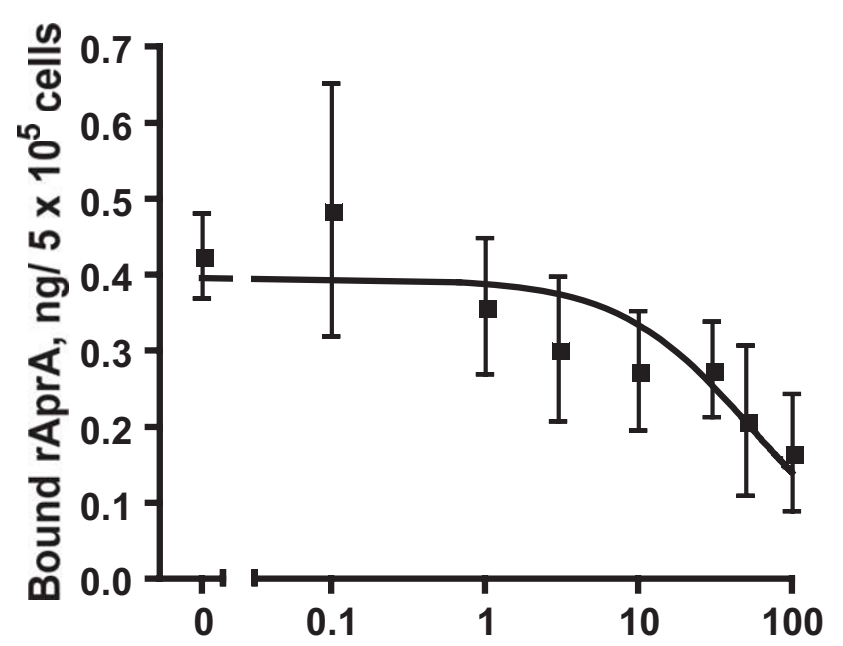

Percent conditioned growth medium added

Figure 7

Endogenous AprA competes with rAprA for binding to cells. The binding of rAprA to aprA-cells was measured in the presence of the indicated concentrations of wild-type conditioned growth medium from cells at $10^{7}$ cells $/ \mathrm{ml}$, where the AprA concentration is $0.3 \mu \mathrm{g} / \mathrm{ml}$. Values are mean \pm SEM $(n=4)$. The line is a curve fit of a sigmoidal dose response curve. both AprA and CfaD, appears to have the same activity as rAprA, and thus has effectively less proliferation inhibiting activity than one would predict. This suggests that there may be some proliferation promoting activity in conditioned growth medium that counteracts the effects of AprA and CfaD. This proliferation promoting activity may well be due to a secreted growth factor activity (the factor has not been identified) that has been observed in Dictyostelium conditioned growth medium [37].

Wild-type cells show roughly steady-state binding after 10 minutes of incubation with rAprA, which is similar to the binding kinetics observed for countin [32] and conditioned medium factor (CMF) to Dictyostelium cells [16]. We found that recombinant AprA binds to wild-type cells with a $K_{D}$ of $\sim 2.6 \mathrm{nM}$. This is stronger than the $\sim 150 \mathrm{nM}$ $\mathrm{K}_{\mathrm{D}}$ observed for folate binding to Dictyostelium cells [38], but quite similar to the $2.1 \mathrm{nM} \mathrm{K}_{\mathrm{D}}$ that we observed for CMF binding [16], and weaker than the 490 pM for CF50 binding [27], or $60 \mathrm{pM}$ for countin binding [32]. Depending on the cell type, we observed $\sim 6-9 \times 10^{4}$ AprA binding sites/cell. Although this is much higher than the 5060 countin or CF50 binding sites/cell [27,32], this is similar to the $\sim 6 \times 10^{4}$ folate binding sites/cell [38] or $\sim 4 \times$ $10^{4} \mathrm{CMF}$ binding sites/cell [16]. Together, this suggests that the binding timecourse, $\mathrm{K}_{\mathrm{D}}$, and number of binding sites/cell for AprA binding to cells are all within the range seen for the binding of other ligands to Dictyostelium cells. At $10^{7}$ cells $/ \mathrm{ml}$, where the extracellular AprA concentration is $0.3 \mu \mathrm{g} / \mathrm{ml}$, solving for the number of occupied cellsurface receptors using our observed $\mathrm{K}_{\mathrm{D}}$ and Bmax for wild-type cells, we see that there will be $\sim 40,000$ occupied receptors, or roughly $2 / 3$ of the receptors will be occupied. This would then allow a strong activation of pathways downstream from the AprA receptor.

Although not statistically significant, it appears that aprAand $c f a D^{-}$cells have somewhat more AprA receptors than wild-type or $\mathrm{crlA}^{-}$cells, and that the AprA receptors in $a p r A^{-}$ and $c f a D^{-}$cells have a lower $\mathrm{K}_{\mathrm{D}}$ (stronger binding) than the receptors in wild-type or $\mathrm{crlA}^{-}$cells. A possible explanation for this is that there may be some degree of AprA-induced receptor desensitization and down regulation in wild-type and $\mathrm{crlA}$ - cells, and that $\mathrm{CfaD}$ is necessary for this effect. 
AprA and $\mathrm{CfaD}$ appear to be part of the same extracellular complex, and the presence of AprA is required for $\mathrm{rCfaD}$ to be able to slow proliferation [30], and conversely the presence of $\mathrm{CfaD}$ is needed for rAprA to slow proliferation (Figure 2A). However, rAprA shows roughly normal binding to cells in the absence of $\mathrm{CfaD}$ (Figures 4 and 5). This suggests that $\mathrm{CfaD}$ does not regulate AprA's proliferationslowing activity by regulating its ability to bind to cells, but rather $\mathrm{CfaD}$ activates some pathway downstream of AprA binding that permits AprA signaling. This is strikingly similar to what we observed for countin and CF50, two protein components of the extracellular signal CF [27]. Countin and CF50 need each other for activity, but still bind to cells in the other's absence [27]. rAprA also needs the presence of the receptor-like protein CrlA to slow proliferation (Figure 2A), but surprisingly rAprA shows roughly normal binding to $\mathrm{crlA}$ - cells (Figures 5 and 6). $\mathrm{rCfaD}$ slows the proliferation of $\mathrm{crlA}$ - cells, although to a lesser extent than $\mathrm{rCfaD}$ slows wild-type or $c f a D^{-}$cells [30]. This suggests that CrlA is neither the AprA nor the $\mathrm{CfaD}$ receptor, but rather is part of a different pathway that for unknown reasons regulates the ability of AprA and $\mathrm{CfaD}$ to function as chalones to slow proliferation.

\section{Conclusion}

Together, the data suggest that AprA functions as an autocrine proliferation-inhibiting factor by binding to cell surface receptors. Like $\mathrm{CfaD}$, the concentration of AprA increases with cell density, and also like $\mathrm{CfaD}$, AprA slows but does not completely stop proliferation. Although AprA requires $\mathrm{CfaD}$ for activity, and the two factors potentiate each other's activity, AprA does not require CfaD to bind to cells, suggesting the possibility that cells have an AprA receptor and a CfaD receptor, and activation of both receptors is required to slow proliferation. We previously found that $\mathrm{crlA}$ - cells are sensitive to $\mathrm{CfaD}$. Combined with the results presented here, this suggests that CrlA is not the AprA or CfaD receptor, and may be the receptor for an unknown third factor that is required for AprA and CfaD activity.

\section{Authors' contributions}

JMC carried out the binding assays and drafted parts of the manuscript. DB prepared recombinant AprA, did the AprA quantitation assays, and drafted parts of the manuscript. JEP did proliferation inhibition assays. RHG conceived the study, participated in the design of the study, performed statistical analysis, and helped to draft the manuscript. All authors read and approved the final manuscript.

\section{Acknowledgements}

We thank Dale Hereld for the crlA- cells, Jeff Crawford for recombinant human serum amyloid $P$, and Darrell Pilling for helpful suggestions. This work was supported by the National Institutes of Health grant GM074990.

\section{References}

I. Gomer RH: Not being the wrong size. Nat Rev Mol Cell Biol 200I, 2(I):48-54

2. Gamer L, Nove J, Rosen V: Return of the Chalones. Dev Cell 2003, 4:|43-15I.

3. Yuen IS, Gomer RH: Cell density-sensing in Dictyostelium by means of the accumulation rate, diffusion coefficient and activity threshold of a protein secreted by starved cells. J Theor Biol 1994, 167:273-282.

4. Lee S, McPherron A: Myostatin and the control of skeletal muscle mass. Curr Opin Genet Dev 1999, 9(5):604-607.

5. Thomas M, Langley B, Berry C, Sharma M, Kirk S, Bass J, Kambadur $\mathrm{R}$ : Myostatin, a negative regulator of muscle growth, functions by inhibiting myoblast proliferation. I Biol Chem 2000, 275(5I):40235-40234.

6. McPherron A, Lee S: Double muscling in cattle due to mutations in the myostatin gene. Proc Natl Acad Sci USA 1997, 94(23): 12457-1246I.

7. Mosher DS, Quignon P, Bustamante CD, Sutter NB, Mellersh CS, Parker HG, Ostrander EA: A mutation in the myostatin gene increases muscle mass and enhances racing performance in heterozygote dogs. PLoS Genet 2007, 3(5):e79.

8. De Groot LJ: What controls thyroid growth - That is, thyroid size? In Control of the thyroid gland Volume 26I. Edited by: Ekholm R, Kohn LD, Wollman SH. New York: Plenum Press; 1989:5-10.

9. Dumont JE, Lefort A, Libert F, Parmentier M, Raspe E, Reuse S, Maenhaut $\mathrm{C}$, Roger $\mathrm{P}$, Corvilain $\mathrm{E}$, Laurent $\mathrm{E}$, et al.: Transducing systems in the control of human thyroid cell function, proliferation and differentiation. In Control of the thyroid gland Volume 261. Edited by: Ekholm R, Kohn LD, Wollman SH. New York: Plenum Press; 1989:357-372.

10. Halaas JL, Gajiwala KS, Maffei M, Cohen SL, Chait BT, Rabinowitz D, Lallone RL, Burley SK, Friedman JM: Weight-reducing effects of the plasma protein encoded by the obese gene. Science 1995, 269(5223):543-546.

II. Schwartz M, Woods S, Porte DJ, Seeley R, Baskin D: Central nervous system control of food intake. Nature 2000, 404(6778):66|-67I.

12. Michalopoulos GK, DeFrances M: Liver regeneration. Adv Biochem Eng Biotechnol 2005, 93: I01-134.

13. Metcalf $D$ : Restricted growth capacity of multiple spleen grafts. Transplantation 1964, 2:387-392.

14. Mehdy MC, Firtel RA: A secreted factor and cyclic AMP jointly regulate cell-type-specific gene expression in Dictyostelium discoideum. Mol Cell Biol 1985, 5:705-7। 3.

15. Gomer RH, Yuen IS, Firtel RA: A secreted $80 \times 10^{3} \mathrm{M}_{\mathrm{r}}$ protein mediates sensing of cell density and the onset of development in Dictyostelium. Development 1991, I I 2:269-278.

16. Jain R, Gomer RH: A developmentally regulated cell surface receptor for a density-sensing factor in Dictyostelium. J Biol Chem 1994, 269(March 25):9128-9136.

17. Jain R, Yuen IS, Taphouse CR, Gomer RH: A density-sensing factor controls development in Dictyostelium. Genes Dev 1992, 6(3):390-400.

18. Yuen IS, Jain R, Bishop JD, Lindsey DF, Deery WJ, Van Haastert PJM, Gomer RH: A density-sensing factor regulates signal transduction in Dictyostelium. J Cell Biol 1995, I29(5): I 25 |- 1262.

19. Shaffer BM: Variability of behavior of aggregating cellular slime moulds. Quart J Micr Sci 1957, 98:393-405.

20. Brock DA, Gomer RH: A cell-counting factor regulating structure size in Dictyostelium. Genes Dev 1999, 13(15):1960-1969.

21. Roisin-Bouffay C, Jang W, Gomer RH: A precise group size in Dictyostelium is generated by a cell-counting factor modulating cell-cell adhesion. Mol Cell 2000, 6:953-959.

22. Tang L, Gao T, McCollum C, Jang W, Vickers MG, Ammann R, Gomer $\mathrm{RH}$ : A cell number-counting factor regulates the cytoskeleton and cell motility in Dictyostelium. Proc Natl Acad Sci USA 2002, 99(3): $137 \mid-1376$.

23. Gao T, Knecht D, Tang L, Hatton RD, Gomer R: A cell number counting factor regulates Akt/Protein Kinase $B$ to regulate group size in Dictyostelium discoideum group size. Eukaryotic Cell 2004, 3(5): I I76-I I84.

24. Jang W, Gomer RH: Exposure of cells to a cell-number counting factor decreases the activity of glucose-6-phosphatase to decrease intracellular glucose levels in Dictyostelium. Eukaryotic Cell 2005, 4(6):991-998. 
25. Jang W, Gomer RH: A protein in crude cytosol regulates glucose-6-phosphatase activity in crude microsomes to regulate group size in Dictyostelium. J Biol Chem 2006, 28 I(24): I6377-I6383.

26. Brock DA, Hatton RD, Giurgiutiu D-V, Scott B, Jang W, Ammann R, Gomer RH: CF45-I, a secreted protein which participates in group size regulation in Dictyostelium. Eukaryotic Cell 2003, 2:788-797.

27. Brock DA, Ehrenman K, Ammann R, Tang Y, Gomer RH: Two components of a secreted cell-number counting factor bind to cells and have opposing effects on CAMP signal transduction in Dictyostelium. J Biol Chem 2003, 278:52262-52272.

28. Brock DA, van Egmond WN, Shamoo Y, Hatton RD, Gomer RH: A 60-kilodalton protein component of the counting factor complex regulates group size in Dictyostelium discoideum. Eukaryot Cell 2006, 5(9): $1532-1538$.

29. Brock DA, Gomer RH: A secreted factor represses cell proliferation in Dictyostelium. Development 2005, I 32(20):4553-4562.

30. Bakthavatsalam D, Brock DA, Nikravan NN, Houston KD, Hatton $\mathrm{RD}$, Gomer RH: The secreted Dictyostelium protein CfaD is a chalone. J Cell Science 2008, I 21:2473-2480.

31. Raisley B, Zhang M, Hereld D, Hadwiger J: A cAMP receptor-like $G$ protein-coupled receptor with roles in growth regulation and development. Dev Biol 2004, 265(2):433-445.

32. Gao T, Ehrenman K, Tang L, Leippe M, Brock DA, Gomer RH: Cells respond to and bind countin, a component of a multisubunit cell number counting factor. J Biol Chem 2002, 277(36):32596-32605.

33. Brock DA, Hatton RD, Giurgiutiu D-V, Scott B, Ammann R, Gomer $\mathrm{RH}$ : The different components of a multisubunit cell numbercounting factor have both unique and overlapping functions. Development 2002, I 29:3657-3668.

34. Cheng Y, Prusoff WH: Relationship between the inhibition constant $(K I)$ and the concentration of inhibitor which causes 50 per cent inhibition (150) of an enzymatic reaction. Biochem Pharmacol 1973, 22(23):3099-3108.

35. Sussman R, Sussman M: Cultivation of Dictyostelium discoideum in axenic culture. Biochem Biophys Res Comm 1967, 29:53-55.

36. Clarke M, Dominguez N, Yuen IS, Gomer RH: Growing and starving Dictyostelium cells produce distinct density-sensing factors. Dev Biol 1992, 152:403-406.

37. Whitbread JA, Sims M, Katz ER: Evidence for the Presence of a Growth Factor in Dictyostelium discoideum. Dev Genetics I99I, | 2:78-8|.

38. Wurster B, Butz U: Reversible binding of the chemoattractant folic acid to cells of Dictyostelium discoideum. Eur J Biochem |980, 109:6|3-6|8.

Publish with Bio Med Central and every scientist can read your work free of charge

"BioMed Central will be the most significant development for disseminating the results of biomedical research in our lifetime. "

Sir Paul Nurse, Cancer Research UK

Your research papers will be:

- available free of charge to the entire biomedical community

- peer reviewed and published immediately upon acceptance

- cited in PubMed and archived on PubMed Central

- yours - you keep the copyright

Submit your manuscript here:

http://www.biomedcentral.com/info/publishing_adv.asp
BioMedcentral 